\title{
Implicit Learning in Second Language Acquisition: Insights from Neuroscientific Data
}

\author{
Nermin Hosny Yusuf \\ English and Scientific Methods Department, The German University in Cairo, Cairo, Egypt
}

Email address:

nermin.yusuf@yahoo.com

To cite this article:

Nermin Hosny Yusuf. Implicit Learning in Second Language Acquisition: Insights from Neuroscientific Data. Communication and Linguistics Studies. Vol. 7, No. 2, 2021, pp. 21-30. doi: 10.11648/j.cls.20210702.11

Received: March 15, 2021; Accepted: April 6, 2021; Published: May 14, 2021

\begin{abstract}
It is an ultimate goal for second language learners to attain a high-level of proficiency and produce L2 accurately as well as fluently. Yet, according to second language learning enormity particularly in a later stage, a considerable number of learners may experience excruciating difficulties. Suffice it to mention that some learners may not even succeed in developing language rudiments. To ascertain the learners' potential, second language acquisition theories have, for long, attempted to account for the difficulties faced by second language learners who tend to think and produce language in a rule-governed way. Inherent to such theories, explicit versus implicit learning approaches attempted to uncover the associated factors affecting second language learning. Accordingly, this has amassed a growing body of research over the issue of implicit learning which has been investigated in various disciplines including SLA and pedagogy, psycholinguistics, and cognitive and neuroscience. This paper places focus on implicit learning highlighting its importance in second language learning as well as its benefits which extend to language automaticity. The paper presents studies probing the effectiveness of implicit learning on various levels; after which neuroscientific data is presented to account for the advantages and development of implicit learning explicating the memory systems underpinning the learning process as well as the neural processes lying at the core therein. Finally, implications are provided.
\end{abstract}

Keywords: Implicit Learning, Automaticity, Procedural Memory, Implicit Competence

\section{Introduction}

Attaining a rapid, fluent, accurate and effortless performance in second language (L2) has long been an ultimate and a fundamental goal to second language learners. As of yet, L2 attainment is not without circumscription since learning an L2 is conspicuously different than learning an L1 as well as is incomparable with respect to proficiency and the level of difficulty a learner encounters. Unlike L1, second language learning normally poses a difficulty for a learner especially after childhood. In other words, the process of second language learning, particularly at a later stage, is usually more effortful than L1 [1]. That said, a myriad of investigations follows therefrom.

Seemingly, the inadequacy of second language teaching approaches is insofar as preclusive to L2 mastery. That is, the majority of the teaching approaches, regardless of the techniques used in implementing their goals, mainly focused on vocabulary and grammatical rules' acquisition ignoring the contextual use, pragmatics and formulaic sequences of the language. For example, while some teaching approaches depended mainly on explicit instruction and emphasis on grammatical rules (i.e. The Grammar Translation Method which focused on grammatical rules, memorization of vocabulary, and translation from L1 to L2), others depended on oral drills and repetition (i.e. The Audiolingual Method which is characterized by structure-based dialogue form of teaching, memorization of set of phrases, use of repetitive drills, little/no grammatical explanation, and emphasis on form rather than meaning; The Direct Method which depends on oral interaction, little analysis of grammatical rules, and spontaneous use of language). This urged the need for other teaching approaches to deviate from the traditional explicit instructions and from oral drills to a more focus on the learner's abilities (i.e. Suggestopedia which mainly focuses on increasing the learner's perception of his/her learning abilities; The Silent Way which is characterized by problemsolving, discovery and creation rather than repetition). As 
inefficient as the said approaches were, other recent approaches were presented with the aim of simulating real interactions and attending to meaning rather than form in order to enhance the communication skills of learners (i.e. The Communicative Approach; The Natural Approach which is a function-centered dialogue form of teaching). Heretofore, there is no consensus on an L2-native-like attainment approach.

Further SLA investigations held explicit/implicit instruction at the core thereof. As early as 1977, Krashen [2-5] pointed out that learning a second language involves two independent processes, namely acquisition and learning. While learning is an intentional process which requires attention and awareness, acquisition, in contrast, refers to incidental unconscious learning. To elucidate, in the acquisition process, knowledge is processed implicitly; contrastively, the learning process is dependent on explicit knowledge. As a premise, explicit knowledge, unlike implicit knowledge which a person is normally unaware of its existence [6], is the type of knowledge that a person consciously know and are aware of using [7]. In principle, explicit learning is defined as "learning to think and talk about the language system in symbolic terms - in terms of rules and their exceptions" [8, p. 188]. Examples of explicit knowledge include "when a student selects a particular theorem to solve a geometry problem" or "when the language learner consults a grammar book in order to find the first person singular form of a particular verb" [6, p. 319].

Parallel to Krashen's proposition, at one extreme, it is presumed that explicit learning is necessary in second language acquisition particularly after childhood, in that it aids achieving a high-level performance [9]. At the other extreme, it is presumed that L2, like L1, is learned implicitly via interconnections between linguistic forms and their associative functions [10] since, seemingly, advanced language learners who attain a high level of L2 proficiency are normally unaware of the explicit L2 rules despite their intuitive understanding [11]. To this end, a substantial amount of research has been conducted on the effect of explicit/implicit teaching on second language acquisition. At one end of the spectrum, while some studies supported explicit learning [12-14], others concluded that explicit learning has little effect on the acquisition process [15-17]. At the other end, implicit learning has been brought to the fore.

\section{Implicit Learning}

\subsection{Implicit Learning Defined}

Implicit learning was originally coined by Reber [18] referring to it as an unconscious process which occurs without intention; further, Reber [19, p. 15433] postulates that during implicit learning, "abstract knowledge about a complex stimulus domain can be acquired and represented outside of consciousness". In a similar vein, implicit learning, according to Rod Ellis [20] is defined as the knowledge that can be acquired without awareness, can be accessed and processed automatically, and cannot be verbalized. Put another way, implicit learning occurs in an unconscious and incidental manner [21] with automatic processing as a core characteristic thereof [20]. Similarly, Leung and Williams [22] posit that implicit learning occurs irrespective of awareness and regardless of the intention of a learner. That said, awareness and intentionality are two factorial notions central to implicit learning.

Examples of implicit learning include perception of socialization [19], musical regularities and first language acquisition [19]. In first language acquisition, according to Nick Ellis [23, p. 1], a child acquires language implicitly by mainly interacting with their caregivers. This results in an implicit automatic acquisition of the language where a child is incapable of consciously describing any rule they acquired. Nick Ellis, further elucidates: "ask a young child how to form a plural and she says she does not know; ask her 'here is a wug, here is another wug, what have you got?' and she is able to reply, "two wugs.",

\subsection{Literature Review on Implicit Learning}

The possibility of learning implicitly has been noticed in a number of studies on various levels. That is, a realm of semantic, syntactic, phonological, grammatical, neurological and form-meaning acquisition using both natural languages as well as artificial ones have been investigated in relation to implicit learning.

In an investigation of word order implicit learning, Francis et al. [24] conducted an experiment on adult native speakers of English. Participants were asked to perform oral readings for three-word structure patterns. Participants were grouped into two groups where one of the groups was introduced to noun-noun-verb sequences and the other group was exposed to verb-noun-noun sequences. All sequences were artificial ones which do not occur in the English language. Oral readings were conducted in two phases: the training phase and the test phase. It was found that subjects implicitly acquired the sequences of the trained strings as well as other untrained ones. This shows that adults can implicitly acquire new word-order patterns that are, further, generalizable to other untrained ones.

On the form-meaning level, Leung and Williams [22] conducted an experiment to investigate if implicit learning occurs at form-meaning mapping level where determiners are correlated with thematic roles of the accompanying nouns. To this end, 25 English native speaking participants were introduced to four artificial articles ( $g i, r o, u l$, and $n e$ ). Participants were advised that $g i$ and ro were used with adults; in contrast, $u l$ and $n e$ were used with children. Yet, the thematic roles of the articles remained unknown to the participants. In point of fact, $g i$ and $u l$ were used with agents (such as active roles of a person) while ro and ne were used with patients (such as passive roles). Participants were provided with a training phase followed by a test phase. In the training phase, they were familiarized with the articles and sentence structures using sample pictures. In the 
reaction-time test phase, they were shown a picture accompanied with an audio statement and were asked to identify the person in the picture according to the audio and the use of articles. Following this, an interview was held to check the awareness of participants. Despite the correct responses, the interviews revealed that $80 \%$ of participants remained unaware of the system hidden rules (i.e. correlation between the determiners and their thematic roles); this is also despite the significantly quick time response in comparison to their reaction time when the rules were reversed in a second trial. Accordingly, Leung and Williams concluded that participants were able to acquire the form-meaning connections implicitly.

On the semantic level, Williams [25] conducted an experiment; in this experiment, 37 participants from different L1 backgrounds were exposed to an artificial micro-language which contained 8 nouns and 8 determiners. Following this, the participants were requested to complete three tasks: word repetition, indication of a living/non-living organism status, and word translation. Participants were, thereafter, introduced to an English phrase and were asked to choose between two translations: one with a determiner with the correct animacy and another with an incorrect animacy. Participants were found to choose more often the correct answer and were found to perform in a remarkable manner that could not possibly be subject to chance. It was concluded, hence, that the results implicated implicit learning.

These findings were extended to Kerz et al. [26] who conducted an experiment to investigate the extent to which adults can acquire L2 implicitly. Data were collected and analyzed from 112 participants who were divided into four groups according to their age: 19-28, 29-48, 49-68, 68+, respectively. Four artificial determiners ( $h u l$, rel, hult and relt) were used in the experiment. While hul and rel indicated distance and inanimacy, hult and relt encoded distance and animacy. Participants were only introduced to hul and rel; hence, the role of animacy remained hidden. Following this, participants were introduced to 16 determiner-noun compounds using short narratives. In a later phase, subjects were to perform a cloze test followed by a two-alternative forced choice (2AFC) task using another 16 determiner-noun combinations. Next, participants were asked to report on their awareness of the hidden rule. It was found out that a significant number of the participants were capable of acquiring the hidden rule without awareness. This holds support for the ability of L2 adult learners to implicitly acquire language on the semantic level.

Using natural language, in another line of research, in their study, Segalowitz, Segalowitz, and Wood [1] analyzed the responses of 105 English-speaking French learners. Segalowitz, Segalowitz, and Wood aimed at finding the effect of practice on language automaticity by providing the participants with French vocabulary classroom practices for two semesters. Throughout the academic year, six sessions were held to test the participants' performance via computerbased lexical decision task. The results yielded language automaticity; yet, separate to this strand of finding, a particularly surprising and noteworthy finding was that the vocabulary, which were not the focus of the learning process but recurred naturally in the activities, were learned in a more efficient manner compared to the vocabulary that were given attention to. This particular finding is highly supportive of the superiority of implicit learning to explicit one.

On the grammatical level, implicit learning of novel verbs and argument structure word order was investigated in a study conducted by Casenhiser and Goldberg [27]. In this study, novel non-English constructions were created, aided with associative meaning, and introduced to 51 native English speaking children. The sentences were introduced via video clips. Overall, 16 video clips were used; each including five novel verbs. Using a forced-choice comprehension task, the children were tested by being exposed to two scenes and being required to choose the corresponding scene to the sentence played on audio. Of note, the audio sentences contained novel verbs which were not used in the training phase. It was found that children were able to learn the novel verbs and word order as well as their associated meanings displaying implicit learning of novel verbs and novel phrasal patterns.

On the phonological level, using natural language, Chan and Leung [28] conducted an experiment to examine the possibility of learning L2 word stress regularities implicitly. In this regard, 52 university English learners were recruited for the experiment and were divided into an experimental and control groups. Audio of a set of 16 Spanish verbs were repeatedly introduced to the experimental group in the training phase. Yet, another set of 24 Spanish verbs were used for the testing phase with the assumption of testing the subjects' abilities of transferring the implicit rules acquired in the training phase to the new words in the testing phase. In contrast to the control group, the experimental group performances were above chance. The findings were supportive of implicit learning where participants were capable of transferring the word-stress knowledge to the untrained verbs. These results are thus suggestive of L2 implicit phonological learning on the word-stress level.

In a neurological investigation, Morgan-Short [17] carried an experiment to detect implicit/automatic responses and implicit learning feasibility. Using Event-related potential (ERP) to assess the implicit knowledge of participants, Morgan-Short found ERP effects for the artificial language knowledge acquired implicitly; conversely, no such effects were detected for the participants who received explicit instruction of the rules. In this experiment, participants were divided into two groups: explicit and implicit training conditions, and, accordingly, were introduced to artificial language either explicitly or implicitly. The artificial language comprised 14 words (4 nouns, 4 verbs, 2 adjectives, 2 adverbs and 2 determiners) and its grammar resembled natural language universal grammar. A computer-based board game was used for the training phase where, similar to a chess game, two players are required to move tokens in order to capture the other player's tokens. Whereas the explicit training group was exposed to a version of the game in which 
metalinguistic information was explicitly stated with few examples, the implicit training group was exposed to the artificial language via meaningful examples only. From a neurolinguistics perspective, EEG $(500 \mathrm{~Hz})$ was recorded and Event-related potential (ERP) was administered, to account for the participants' neurolinguistics processing, at two points: at a low proficiency level attainment and at the end of the training phase. It was presumed that since ERP responses are produced within milliseconds of syntactic and semantic violations, this would predict an unconscious implicit automatic process. For the testing phase, grammaticality judgment tests (GJTs) (during and post ERP sessions), a free response task (a less controlled version of the game) and a debriefing questionnaire (for metalinguistic knowledge and awareness) were used. The results revealed no significant differences between the two groups in low proficiency phase test nor in high proficiency phase test in all measurements. This confirms that explicit learning is not advantageous over implicit learning. Moreover, despite the advanced performance of both groups, ERP was detected only in the implicit training group with regard to phrase structure. This is supportive of implicit learning particularly on the syntactic and morphosyntactic levels. It was also found that the participants with implicit performance outreached the participants with explicit instruction yielding a more nativelike performance.

As seen, evidence supportive of implicit learning abound. In another line of inquiry, having mentioned the automatic performance of a language, in particular, in relation to implicit learning which seemingly leads to an automatic process and production of a language, it is peripheral to shed light on automaticity since it is postulated that a language which is acquired implicitly will result in automaticity and a long-term efficiency [29].

\section{Implicit Learning and Automaticity}

Unlike a controlled process which is slow and under the control and awareness of a subject, automaticity is a quick process which occurs without such awareness and control; through automatic process, and by sufficient mental practice, a skill is well-developed and performed in a quick as well as an accurate manner [30, 31]. An automatic process, according to Bargh [32] has four main characters which are referred to in his work as the four horsemen. The four horsemen of automaticity are: first, awareness which refers to the subject's unawareness of automatic process unlike controlled process; second, intentionality in which case a subject does not necessarily intend to perform the automatic process unlike the controlled process; third, efficiency which indicates that the automatic process is fast and requires less attention than the controlled process; fourth, controllability which stands for the inability to control an automatic process dissimilar to a controlled process.

An exemplary of automaticity is when a person learns to touch-type on a computer keyboard. In the early phase of practicing, typing will be characterized by slowness, effort and frequent errors due to the controlled manner of the process at such a stage. However, as the skill becomes automatized, it will be performed faster and in an error-free manner; importantly, it will be carried out without awareness. In a similar example, Bebko [33] states that "automaticity is the state that, for example, skilled typists attain when they no longer need to think about the individual letters or words being typed. Rather, they execute the task of typing in an automatic way, requiring less mental effort, and can focus, if they wish, on editing or evaluating the content of the material being typed".

Other automatized skills include efficiently playing a musical instrument, effectively driving a car, and speaking an L1. In L2, automaticity is of no less importance as it enhances language proficiency. On this account, Segalowitz, Segalowitz and Wood [1] affirm that unlike the controlled processing of a language skill which is characterized by a slow, inaccurate and less stable performance, an automatized language skill is performed rapidly, accurately and more stable; accordingly, performance of the language becomes mechanical. An example is automatic speech which is "the result of rote learning (often produced without really thinking about the meaning of what is said), which global aphasic and echolalic patients are sometimes able to produce in the absence of any ability to propositionize" [34, p. 5].

Simply put, automatized skills, including language, require a minimal effort, are performed with minimal errors, are highly efficient, and may be done simultaneously with other tasks. This is because, unlike a controlled process which is processed by the declarative memory system, automaticity is processed via the procedural memory system. That said, below, the two memory systems are elaborated with a wider neuroscientific explanation behind the urge of implicit learning.

\section{The Neuroscientific Explanation on the Significance of Implicit Learning}

Presumably, implicit learning is intertwined with the human's brain. It is an intrinsic nature of the brain to extract information even if it was not paid attention to. In this respect, in particular in language learning, Goswami [35] refers to the brain's capabilities to extract language-related information, even when the language is not learnt in an explicit way, due to the fibre connections which encode abstract information and concepts. Hence, the education process should help guide the brain to extract the language structure rules underpinning the knowledge presented.

In neurological investigations, it has been concluded that explicit and implicit learning are represented differently in the brain. While explicit learning is represented in the prefrontal cortex, implicit learning is supported by various areas of perceptual and motor cortex [36]. To elucidate, the brain encompasses two main memory systems for storing information and learning processes which differ in function and neural representation; namely, declarative memory and 
procedural memory. Ullman [37] illustrates the difference between the declarative memory system and the procedural memory system stating that while declarative memory system underlies conscious learning and is subserved by medial temporal lobe regions which are responsible for consolidating memory, the procedural memory, which is represented in various interconnected structures, underlies learning implicitly and unconsciously.

The distinction between declarative and procedural memory is further illustrated by Paradis [38] who explains the link between both procedural and declarative memory, on the one hand, and neural activation, on the other hand. Paradis states that when tasks are declarative-memorydependent (such as explicit knowledge about geography), larger cortical areas are activated indicating the difficulty and effortful processing of the task. Contrarily, in the case of a procedural memory task (such as mastering playing a musical instrument), less cortical areas are activated due to automatization.

The relation between declarative and procedural memory is further clarified by Ullman [37] who posits that even though declarative and procedural memory may interact cooperatively, they also interact competitively. On the one hand, they act cooperatively due to the rapid learning abilities of declarative memory and the internalization capability of the procedural memory. On the other hand, the two memory systems interact competitively as learning in one system may lead to suppression to the other system. This view is further supported by Paradis [34, pp. 129-130] who asserts that "The consequent reliance on declarative memory renders the appropriation of language contingent upon the various factors suggested by authors as being responsible (instead of a neural-based reason) for arduous and eventually poor attainment".

After shedding light on the difference and interactional relation between the declarative and procedural memory, it is now time we shifted to the role they play in the language learning process. In an earlier study, Fabbro [39] argued in favor of procedural memory in the learning process affirming that the procedural memory, due to its highly developed cerebral as well as subcortical structures is the one responsible for both motor skills as well as cognitive skills which the learning process is subsidiary of. In parallel, Paradis [34] refers to the inextricable nature of procedural memory in processing language information implicitly and, subsequently, using it automatically.

Delving more into language learning, and in line with the aforementioned postulations, when L2 learners are explicitly exposed to L2 knowledge and grammar rules, such information gets processed consciously and gets stored in the declarative memory through which a learner consciously retrieves L2 structure rules in language production tasks in a controlled manner [34]. However, implicit learning, which occurs when the attention of the learner is deviated from the focus of learning, is processed by the procedural memory in an automatized way. For example, a learner may acquire, implicitly, the syntactic structure of a language while focusing on the meaning of an utterance. Subsequently, the syntactic structure is internalized, stored implicitly and used automatically. Conversely, when language grammar rules are learnt explicitly, particularly with given attention, the acquisition process is negatively affected and internalization of the language rules is never achieved [38].

Post illustrating automaticity as well as the relation between language and the two memory systems, declarative and procedural, and after highlighting the efficiency of procedural memory in acquiring a language in an implicit way, it is time we highlighted how to develop implicit competence in relation to automaticity and neurolinguistic data.

\section{Developing Implicit Linguistic Competence}

As indicated in the previous paragraphs, neurological explanation and study-related evidence abound for the feasibility as well as the efficiency of implicit learning. At the core of this, it is crucial to develop implicit linguistic competence. According to Paradis [34, p. 3], implicit linguistic competence is defined as

A functional system capable of generating sentences, which is inferred from speakers' systematic verbal behavior. It is inferred that they must have stored in their brains some entity that can be considered as a grammar that allows them to speak the way they do by combining elements in a consistent fashion; they keep this grammar in memory so as to speak in the same way from day to day.

Further, Paradis [34, p. 112] postulates that implicit linguistic learning is achieved by "developing the various components of language structure in parallel, incidentally, without paying attention, and without focusing one's efforts on any specific subcomponent (phonology, morphology, syntax, semantics and the grammatization of the lexicon)". In congruence with Paradis, developing implicit linguistic competence, according to Netten and Germain [40], which occurs unconsciously without the awareness of the learner, is achieved through the frequent use of language structures as well as through learners' concentration on the meaning of the message rather than the form of the language. Netten and Germain's view supports previous views like Krashen's [41] which states that, according to the input hypothesis, learners acquire a language by understanding input that contains structure beyond the learner's competence level. Krashen, further, adds that with repetitive experience, the learning process will automatically occur without having to explicitly highlight the grammatical structures into the input.

\subsection{Implicit Learning, Practice and Automaticity}

Another pivotal factor for the development of implicit linguistic competence is practice/repetition. DeKeyser [42] points to the alternating process in which the explicit input in declarative memory converts to a procedural one with practice. Subsequently, language automaticity will be a 
natural corollary to the implicit linguistic competence achieved through the procedural memory. This theory is in particular pivotal for L2 late learners who might have been exposed to L2 via explicit instructions. Accordingly, even late learners are not disadvantaged from implicit learning and language automaticity.

Like Dekeyeser, Krashen, and Netten and Germain [42, 41, 40], Lee [43] contends that, with a wide array of L2 practice, procedural memory will enhance. Consequently, L2 learners' low proficiency and fluency, which is attributed, according to Lee, to learners' non-automatized language, will enhance resulting in L2 automatization. Moreover, Lee [43, p. 44] argues that a person acquires skills through procedural memory by "repeated execution of a task" which occurs unconsciously without awareness to the time, nature, or procedure by which the knowledge/skill was learned. Likewise, Paradis [38] disputes that automatic processing, in fact, develops and replaces controlled processing through recurrent practice; thus, automaticity is improved. It is worth noting here that declarative knowledge does not transfer to procedural automatic knowledge; however, a computational procedure occurs independently and unconsciously to produce an output. In principle, "Automatization eventually and indirectly results from the actual practice of possibly deliberate actions" [38, p. 44]. In a latter study, Paradis [34] asserts that only through practice a language is internalized into an implicit linguistic competence. Likewise, Segalowitz [44] highlights the importance of language input frequent exposure and repetition to attaining a high level of L2 proficiency and to automatizing language. Morover, he asserts that "what must be repeated is the whole set of mental processes involved in the planning, assembling, and execution" of language input through communicative contexts; "otherwise, the nature of the underlying cognitive processing could change significantly" [44, p. 176]. Segalowitz, further, adds that automatization does not develop from formal language instruction.

Second language acquisition, in general, and structure and syntax acquisition, in particular, were reported by a number of studies to pose a great difficulty. In a similar fashion, acquiring syntax/aspects of grammar, unlike lexicon, in language-deprived cases becomes massively impaired [37, p. 150-151]. Nevertheless, native attainment is not impossible so long as a sufficient amount of L2 exposure is guaranteed. In this regard, learners should be exposed to L2 implicitly, depending on procedural memory, for a native-like attainment. Contrastively, if learners are exposed to L2 explicitly, depending heavily on declarative memory, and given the fact that learning via declarative memory, as mentioned above, may impair the learning process via procedural memory, native language attainment could be, in this case, far from reached

Studies, on both animals and humans, have been conducted to examine the role of practice on automaticity. In a study conducted on rats by Jog et al. [45], it was found that neural changes correlated with changes in the rats' behavior when they underwent a t-maze training task aiming at enhancing procedural memory automatization. In the task, rats commenced running through the maze on hearing an auditory signal until they reached the two-path t-shape; on reaching this divergent point, they had to respond to another auditory signal upon which their direction (left or right) was determined; the rats were rewarded when making the correct choice. Over repetition, the rats' performance enhanced: on the one hand, reaction time as well as movement time since hearing the auditory signal until reaching the goal decreased; on the other hand, the rats' performance accuracy increased. One caveat is that rewarding the brain seems to be not only motivational but also necessary, to a great extent, for enhancing its functions. Importantly, repetition seems to be an essential key in automatizing a skill. Lee [43], commenting on Jog et al.'s [45] experiment, points out that the rats' learning behavior parallels with the enhanced behavior and proficiency of L2 learners (i.e. enhanced utterance initiation, conversational turn-taking reduced reaction time, increased comprehension and production skills, and increased accuracy of language performance).

In another study conducted on humans to investigate the effect of practice on automaticity, it was concluded that practice can, in fact, lead to automaticity by altering the mechanisms of the brain to processing the information by areas other than those which are responsible for decoding the explicit knowledge [46]. In the fMRI study, it was shown that adults who were explicitly taught mathematical rules for long multiplications had alternation in brain activated areas from inferior frontal gyrus to angular gyrus. To elucidate, being demanding in the beginning of the learning process, the mathematical rules were presented in the frontal gyrus; however, when practiced, such mathematical rules became automatized in the angular gyrus, thus, requiring less time and effort to process.

Possible supports for the importance of practice are provided through comparing practice between L1 and L2. In this regard, it has been noted that L2 is not sufficiently practiced as L1. That is, a child spends most of his/her daytime acquiring and practicing their L1. Unlike this situation, learners, particularly late learners, rarely have enough time to practice their L2 [44]. To this end, Erricson et al. [47] postulate that 10,000 hours are needed for a high level language expertise to be achieved. Central to this notion, Hernandez's situation is an exemplary. After having travelled to Brazil for university studies, and after being immersed in a new third language (Portuguese), Hernandez [48], in his twenties, reported that he was mistaken for a native speaker due to the proficiency he obtained within only two years. On the other hand, when he went back to his homeland he found difficulty in using his mother tongue, Spanish, with a comparable fluency to that before learning Portuguese. Hernandez concluded that a language is prone to being lost, or majorly affected/laboriously accessed, due to various factors. At the core of these factors lies the role of practice which seems to be part and parcel of a language high proficiency.

Other supports for the pivotal role of practice are provided 
by neural evidence. From a neurological standpoint, Goswami [35] asserts that repetitive experience leads to naturally stronger realization/acquisition of that experience. That is, when the brain responds to similar multiple stimuli, the fibre connections which occur to encode such stimuli become stronger. Further, Goswami provides an example of piano playing and highlights the importance of practice and repetition in mastering it. Goswami [35, p. 394] clarifies that "the cortical representation of piano tones was found by Pantev and colleagues to be correlated with the amount of time that different individuals spent in piano practice". This is because repetitive synaptic density leads to enhanced learning. Same-like, in L2 learning, practice will unequivocally result in L2 proficiency enhancement and automaticity.

The brain's convergence, divergence and re-convergence processes also provide an insight to the mechanisms occurring in the brain with regards to repetition of a stimulus (in other words, practice). In consequence to the convergence, divergence and re-convergence processes, which occur specifically in the basal ganglia, a cell change can be enforced due to repetitive activation to neurons [49]. To elucidate, on the one hand, in convergence, input from multiple neurons of the neocortex, which receive input from all cerebral cortex areas, converge onto one neuron of striatum (STR) in a selective and precise manner. In divergence, input from a specific part of the neocortex disperse into the striatum forming interconnected neural clusters which is responsible for acquiring responses in the learning process. On the other hand, in re-convergence, striatal neurons re-converge to other target neurons in the globus pallidus (GP)" [43, p. 49]. Through these processes information is acquired and organized in the basal ganglia which has a vital role in the learning process.

In language learning, and in congruence with the above mentioned, Lee [43] asserts that the target language is strengthened by repetitive target language input and production; this helps build stronger synapses in the Basal Ganglia which eventually enables an L2 learner acquire the target language rules through the direct pathways of the basal ganglia. The direct pathway allows for the automatic execution of the target language's grammar rules (i.e. word order and subject-verb agreement).

Simply put, in as much as L2 learner repeats a formula, the neural circuits strengthen due to the strengthened corticobasal ganglia neural connections. On the other side of the coin, this, presumably, also occurs to incorrect formula repetition. In particular, the neural circuits are strengthened when the rules executed by an L2 learner succeed in conveying his/her desired meaning; this happens due to dopamine facilitation through the dopaminergic system. However, if the L2 learner fails to convey his/her intended meaning, other rules will be formulated to achieve the said target. In a similar fashion, neural circuits get strengthened when a positive feedback is provided for an L2 learner; a reversed process occurs for a negative feedback [43]. In congruence with Lee, Bybee [50] disputes that since frequent repetition leads to automatizing grammar, in a similar, however bidirectional, vein, repetition of incorrect language sequence will lead to fossilization as a certain wrong aspect of language gets automatized. On this account, the following lines are dedicated.

\subsection{From Fossilization to Defossilization}

A core characteristic of second language learning is that it fossilizes [51] and does not respond to, nor coincide with, L2 classroom practices [52]. Irresponsive to classroom practices, interlanguage development, according to Skehan [53, p. 351], requires a process where "slow, effortful, and attentiondemanding performance, which may also be error-prone, is progressively replaced by less conscious, easier, automatic, and fast performance". In this regard, implicit learning acquainted by practice may have an un-ignorable effect on interlanguage fossilization.

Fossilization is defined by Lee [43, p. 70] as "what occurs when some aspects of a second language have been proceduralized through the basal ganglia but these elements do not perfectly conform to the rules of the target language". The main characteristics of fossilized language are natural fluidity and rigidity which hark back to Selinker and Selinker, and Harley and Swain [54, 55]. First, natural fluidity is the result of acquiring the target language procedurally -via the procedural memory- which leads to automatizing the language even though such acquisition may include some incorrect linguistic rules. Then, when such language is automatized/fossilized, it becomes rigid to any change as procedural memory is inflexible and resistant to change.

In an opposite direction, Lee [43] advocates the possibility to repair inaccurate acquired language, or to defossilize language, due to two aspects. The first aspect is that procedural memory is influenced by other factors such as declarative memory as they both, anatomically, share the same cortical areas; to elucidate, hippocampus which is responsible for the declarative memory and basal ganglia which subserves the procedural memory are connected and influence each other. Whereas the second aspect is that the brain continues to maintain its plasticity (amenability to neural change); hence, the possibility to defossilize language by such a characteristic is conceivable particularly when motivation co-occurs.

\section{Conclusions}

In this paper, an overview of implicit learning was provided and studies conducted on the effectiveness of implicit learning were reviewed. The studies in this paper show that implicit learning is feasible on various language levels (i.e. phonological, semantic, syntactic, grammatical, form-meaning, neurological). Further, this paper supports the view of why implicit learning, from a scientific standpoint, is essential, since the procedural memory system, which is accountable for implicit learning, has been proved to be responsible for implicit knowledge and more adept at language learning. In effect, processing L2 implicitly via the 
procedural memory allows for high language efficiency as well as language automaticity.

This paper also sheds light on developing implicit linguistic competence which is best developed via implicit exposure to various components to language structures as well as via practice since repetitive synaptic density, resulting from repetitive experience, leads to enhanced learning through building stronger synapses in the Basal Ganglia. This in principle, develops automatic processing of a language as well as further offers insights into interlanguage defossilization.

Even though the concept of implicit learning harks back to 1967, there is a longstanding lack of this approach and the implementation thereof is far from achieved. On this account, the studies reviewed in this paper, along with the neuroscientific evidence, provide insights into the importance of implicit learning in second language approaches. An advantage of this approach is that learners can acquire a second language in an effortless manner. Another advantage is to facilitate interlanguage development and assist the learner in this phase to shift to a more advanced-level learning phase. Moreover, implicit learning is highly advantageous in that it leads to automaticity. In effect, a learner can use L2 efficiently and fluently with minimal errors.

In second language acquisition, hence, it is postulated that an L2 should be learnt in a way that mimics first language acquisition. It is of high importance to consider implicit learning, at least in part, in teaching approaches. One main pedagogical implication is to integrate implicit learning into L2 curricula and EFL programs, in particular in adult learning in an attempt to alter neural mechanisms and process language via the procedural memory, thus assisting adult learners in achieving a high level of proficiency and reaching language automaticity. That said, curricula developers should place more focus on specifically designed material that allows for implicit learning. In a similar vein, various teaching methodologies hinging on implicit learning should be adopted by educators.

Another implication is to develop implicit competence. Curricula developers should, along the same line, consider implicit unconscious repetition and practice of language structures using various receptive and production tasks. This is due to the fact that through frequent use of language structures, a learner can develop implicit competence. Adding to this, second language structure repeated exposure and production does not only lead to implicit learning and developing implicit competence, but leads to further transformation of explicit knowledge into implicit knowledge as well. This is highly advantageous to adults with previous explicit exposure to second language. Through repetition, a learner's second language is also postulated to get automatized, thus resulting in an effortless, fluent error-free language production.

In accordance with the aforementioned implications, second language learners should not be confined to explicit learning materials. They should rather expose themselves to a myriad of other target language resources and authentic materials (e.g. Youtube videos, talk shows, movies, songs, audio, magazine articles, scripts, stories, graded readers, news, etc...). This is to provide learners with second language input and give a chance for the learner's brain, via L2 high exposure, to notice language structure, unconsciously extract language rules, acquire the language implicitly, and thereby use language automatically.

To recapitulate, in culminating on a solution to circumvent second language learning difficulties, this paper supports the implementation of implicit learning in second language approaches. Since evidence accumulated on the effectiveness of implicit learning in second language process and its ability to facilitate language acquisition, attenuate second language learning difficulties, and automatize language.

\section{References}

[1] Segalowitz, S., Segalowitz, N. \& Wood, A. (1998). Assessing the development of automaticity in second language word recognition. Applied Psycholinguistics, 19, 53-67. https://doi.org/10.1017/S0142716400010572.

[2] Krashen, S. (1977). The Monitor Model for adult second language performance. In $M$. Burt, $H$. Dulay \& $M$. Finocchiaro (Eds.), Viewpoints on English as a Second Language: In honor of James E. Alatis (pp. 152-161). Regents Publishing.

[3] Krashen, S. (1979). The Monitor Model for second language acquisition. In R. Gingras (Ed.), Second language acquisition and foreign language teaching (pp. 1-26). VA: Center for Applied Linguistics.

[4] Krashen, S. (1981). Second language acquisition and second language learning. Pergamon.

[5] Krashen, S. (1994). The input hypothesis and its rivals. In N. C. Ellis (Ed.), Implicit and explicit learning of languages (pp. 45-77). Academic Press.

[6] Williams, J. N. (2009). Implicit learning in second language acquisition. In C. R. Williams \& T. K. Bhatia (Eds.), The new handbook of second language acquisition (pp. 319-353). Emerald Group Publishing Limited.

[7] Dienes, Z., \& Perner, J. (1999). A theory of implicit and explicit knowledge. Behavioural and Brain Sciences, 22, 735808. http://doi.org/10.1017/S0140525X99002186.

[8] Andringa, S., \& Rebuschat, P. (2015). New directions in the study of implicit and explicit learning: An introduction. Studies in Second Language Acquisition, 37 (2), 185-196. https://doi.org/10.1017/S027226311500008X.

[9] DeKeyser, R. M. (2000). The robustness of critical period effects in second language acquisition. Studies in Second Language Acquisition, 22, 499-533. http://doi.org/10.1017/S0272263100004022.

[10] Ellis, N. C. (2002). Frequency effects in language processing: A review with implications for theories of implicit and explicit language acquisition. Studies in Second Language Acquisition, 24 http://doi.org/10.1017/S0272263102002024.
143-188. 
[11] Schmidt, R. (2010). Attention, awareness, and individual differences in language learning. In W. M. Chan, S. Chi, K. N. Cin, J. Istanto, M. Nagami, J. W. Sew, T. Suthiwan, \& I. Walker, Proceedings of CLaSIC 2010, Singapore, December 2-4 (pp. 721-737). Singapore: National University of Singapore, Centre for Language Studies.

[12] DeKeyser, R. M. (1995). Learning second language grammar rules: An experiment with a miniature linguistic system. Studies in Second Language Acquisition, 17 (3), 379-410. https://doi.org/10.1017/S027226310001425X.

[13] Ellis, N. C. (1993). Rules and instances in foreign language learning: Interactions of explicit and implicit knowledge. European Journal of Cognitive Psychology, 5 (3), 289-318. https://doi.org/10.1080/09541449308520120.

[14] Robinson, P. (1997). Generalizability and automaticity of second language learning under implicit, incidental, enhanced, and instructed conditions. Studies in Second Language $\begin{array}{llll}\text { Acquisition, } & 19 & \text { (2), 223-247. }\end{array}$ http://doi.org/10.1017/S0272263197002052.

[15] Rosa, E. M., \& Leow, R. P. (2004). Computerized task-based exposure, explicitness, type of feedback, and Spanish L2 development. Modern Language Journal, 88 (2), 192-216. http://doi.org/10.1111/j.0026-7902.2004.00225.x.

[16] Sanz, C., \& Morgan-Short, K. (2005). Explicitness in pedagogical interventions: Input, practice, and feedback. In C. Sanz (Ed.), Mind and Context in Adult Second Language Acquisition: Methods, Theory, and Practice (pp. 234-263). Washington, DC: Georgetown University Press.

[17] Morgan-Short, K. (2007). A neurolinguistic investigation of late-learned second language knowledge: The effects of explicit and implicit conditions. Ph.D. thesis, Georgetown University, http://doi.org/10.13140/RG.2.2.36575.07841.

[18] Reber, A. S. (1967). Implicit learning of artificial grammars. Journal of Verbal Learning and Verbal Behaviour, 6 (6), 855863. https://doi.org/10.1016/S0022-5371(67)80149-X.

[19] Reber, A. S. (2001). Tacit Knowledge, Psychology of. In N. J. Smelser \& P. B. Baltes (Eds.), International Encyclopedia of the Social \& Behavioral Sciences (pp. 15431-15435). Pergamon. https://doi.org/10.1016/B0-08-043076-7/01492-3.

[20] Ellis, R. (2005). Measuring implicit and explicit knowledge of a second language: A psychometric study. Studies in Second Language Acquisition, 27, 141-172. https://doi.org/10.1017/S0272263105050096

[21] Rebuschat, P., \& Williams, J. N. (2013). Implicit learning in second language acquisition. In C. A. Chapelle (Ed.), The encyclopedia of applied linguistics (pp. 1-7). Blackwell Publishing http://doi.org/10.1002/9781405198431.wbeal0529.

[22] Leung, J. H., \& Williams, J. N. (2011). The implicit learning of mappings between forms and contextually derived meanings. Studies in Second Language Acquisition, 33 (1), 33-55. http://doi.org/10.1017/S0272263110000525.

[23] Ellis, N. C. (2015). Implicit and explicit knowledge about language. In J. Cenoz, D. Gorter, S. May (eds.) Encyclopedia of Language and Education ( $3^{\text {rd }}$ ed.). Springer. https://doi.org/10.1007/978-3-319-02325-0_7-1.

[24] Francis, A. P., Schmidt, G. L., Carr, T. H., \& Clegg, B. A.
(2009). Incidental learning of abstract rules for non-dominant word orders. Psychological Research, 73, 60-74. https://doi.org/10.1007/s00426-008-0138-6.

[25] Williams, J. N. (2004). Implicit learning of form-meaning connections. In J. N. Williams, B. VanPatten, S. Rott, \& M. Overstreet (Eds.), Form-meaning connections in second language acquisition (pp. 203-218). Lawrence Erlbaum.

[26] Kerz, E., Wiechmann, D., \& Riedel, F. B. (2017). Implicit learning in the crowd: Investigating the role of awareness in the acquisition of L2 knowledge. Studies in Second Language Acquisition, $\quad 39 \quad$ (4), $\quad$ 711-734. https://doi.org/10.1017/S027226311700002X.

[27] Casenhiser, D., \& Goldberg, A. E. (2005). Fast mapping of a phrasal form and meaning. Developmental Science, 8 (6), $500-508$ https://doi.org/10.1111/j.14677687.2005.00441.x.

[28] Chan, R. K., \& Leung, J. H. (2014). Implicit learning of L2 word stress regularities. Second Language Research, 30 (4), 463-484. https://doi.org/10.1177/0267658313510169.

[29] Nergis, A. (2011). To what extent does neurolinguistics embody EFL teaching methods? Science Direct, 15, 143147.

[30] Shiffrin, R. M., \& Schneider, W. (1977). Controlled and automatic human information processing. II. Perceptual learning, automatic attending, and a general theory. Psychological Review, 84, 127-190.

[31] Schneider, W., Dumais, S., \& Shiffrin, R. (1984). Automatic and control processing and attention. In R. Parasuraman (Ed.), Varieties of attention (pp. 1-27). New York: Academic Press.

[32] Bargh, J. A. (1994). The four horsemen of automaticity: Awareness, intention, efficiency, and control in social cognition. In R. S. Wyer \& T. K. Srull (Eds.), Handbook of social cognition (Vol. 1, pp. 1-40). Hillsdale, NJ: Lawrence Erlbaum Associates, Inc.

[33] Bebko, J. M. (1998). Learning, Language, Memory, and Reading: The Role of Language Automatization and Its Impact on Complex Cognitive Activities. Journal of Deaf Studies and Deaf Education, 3 (1), 4-14.

[34] Paradis, M. (2009). Declarative and Procedural Determinants of Second Languages. The Netherlands: John Benjamins Publishing Co.

[35] Goswami, U. (2008). Principles of Learning, Implications for Teaching: A Cognitive Neuroscience Perspective. Journal of Philosophy of Education, 42 (3-4), 381-399. https://doi.org/10.1093/acprof:oso/9780199600496.003.0023.

[36] Dehaene, S. (2014). Consciousness and the brain: Deciphering how the brain codes our thoughts. Penguin/Random House.

[37] Ullman, M. (2005). A cognitive neuroscience perspective on second language acquisition: methods, theory, and practice. In C. Sanz (Ed.), Mind and Context in Adult Second Language Acquisition (pp. 141-168). Georgetown University.

[38] Paradis, M. (2004). A Neurolinguistic Theory of Bilingualism. The Netherlands: John Benjamins Publishing Co.

[39] Fabbro, F. (1999). The neurolinguistics of bilingualism: An introduction. Hove, UK: Psychology Press. 
[40] Netten, J., \& Germain, C. (2012). A new paradigm for the learning of a second or foreign language: the neurolinguistic approach. Neuroeducation, 1 (1), 85-114. https://doi.org/10.24046/neuroed.20120101.85.

[41] Krashen, S. (1984). Bilingual Education andSecond Language Acquisition Theory. In C. F. Leyba (Ed.), Schooling and Language Minority Students: A Theoretical Framework (pp. 63-126). Los Angeles: Evaluation, Dissemination and Assessment Center, California State University.

[42] DeKeyser, R. (1997). Beyond explicit rule learning: Automatizing second language morphosyntax. Studies in Second Language Acquisition, 19, 195-221. https://doi.org/10.1017/S0272263197002040,

[43] Lee, N. (2004). The neurobiology of procedural memory. In J. H. Schumann, S. E. Crowell, N. E. Jones, N. Lee, S. A. Schuchert, \& L. A. Wood (Eds.), The neurobiology of learning: Perspectives from second language acquisition (pp. 43-73). Mahwah, NJ: Erlbaum.

[44] Segalowitz, N. (2010). Cognitive Bases of Second Language Fluency. New York: Routledge.

[45] Jog, M. S., Kubota, Y, Connolly, C. L, Hillegaart, V., \& Graybiel, A. M. (1999). Building neural representations of habits. Science, 286, 1745-1749.

[46] Delazer, M., Domahs, F., Bartha, L., Brenneis, C., Lochy, A., Trieb, T. and Benke, T. (2003) Learning complex arithmetic an fMRI study, Cognitive Brain Research, 18, 76-88. e62. http://dx.doi.org/10.1017/S0140525X1500031X.
[47] Ericsson, K. A., Krampe, R. T., \& Tesch-Romer, C. (1993). The role of deliberate practice in the acquisition of expert performance. Psychological Review, 100, 363-406.

[48] Hernandez, A. E. (2013). The Bilingual Brain. New York: Oxford university press.

[49] Graybiel, A. M. (1998). The basal ganglia and chunking of action repertoires. Neurobiology of learning and memory, 70, $119-136$.

[50] Bybee, J. (2008). Usage-based grammar and second language acquisition. In P. Robinson \& N. C. Ellis (Eds.), Handbook of cognitive linguistics and second language acquisition (pp. 216-236). New York: Routledge.

[51] Tarone, E. (2010). Interlanguage. In M. Berns, \& K. Brown (Eds.), Concise Encyclopedia of Applied Linguistics (pp. 134139). UK: Elsevier Ltd.

[52] Selinker, L. (1972). 'Interlanguage.' IRAL 10, 209-231.

[53] Skehan, P. (2010). Second and Foreign Language Learning and Teaching. In M. Berns, \& K. Brown, Concise Encyclopedia of Applied Linguistics (pp. 350-357). UK: Elsevier Ltd.

[54] Selinker, L., \& Selinker, P. (1972). An annotated bibliography of U.S. Ph. D. dissertations in contrastive linguistics. Center for Applied Linguistics.

[55] Harley, B., \& Swain, M. (1978). An analysis of the verb system by young learners of French. Interlanguage Studies $\begin{array}{llll}\text { Bulletin, } & 3 & \text { (1), 35-79. }\end{array}$ https://doi.org/10.1017/S0272263100000085. 